Research article

\title{
Multispecies landscape functional connectivity enhances local bird species' diversity in a highly fragmented landscape
}

\author{
Pedro A. Salgueiro a,b,e,*, Francesco Valerio ${ }^{\text {a,c,e }}$, Carmo Silva ${ }^{\text {a,d,e }}$, António Mira ${ }^{\text {a,d,e }}$, \\ João E. Rabaça ${ }^{\text {b, }, \text {,e }}$, Sara M. Santos ${ }^{\text {a,d,e }}$ \\ ${ }^{\text {a } U B C ~-~ C o n s e r v a t i o n ~ B i o l o g y ~ L a b, ~ P o r t u g a l ~}$ \\ ${ }^{\mathrm{b}}$ LabOr - Laboratory of Ornithology, Portugal \\ ${ }^{\mathrm{c}}$ CIBIO-UE - Research Center in Biodiversity and Genetic Resources, Pole of Évora, Portugal \\ ${ }^{\mathrm{d}}$ MED-Mediterranean Institute for Agriculture, Environment and Development, Instituto de Investigação e Formação Avançada, USA \\ e Department of Biology, University of Évora. Mitra, 7002-554, Évora, Portugal
}

\section{A R T I C L E I N F O}

\section{Keywords:}

Community assemblage

Metacommunity

Production forests

Forest management

Habitat quality

Landscape filtering

\begin{abstract}
A B S T R A C T
Local species assemblages are likely the result of habitat and landscape filtering. However, there is still limited knowledge on how landscape functional connectivity complements habitat attributes in mediating local species assemblages in real-world fragmented landscapes. In this study, we set up a non-manipulative experimental design in a standard production forest to demonstrate how functional connectivity determines the spatial distribution of a bird community. We test single- and multispecies spatially explicit, landscape functional connectivity models framed within the circuit theory, considering also patch attributes describing habitat size and quality, to weight their effects on species occurrence and community assemblage. We found that single-species functional connectivity effects contributed positively for occurrence of each species. However, they rarely provided competing alternatives in predicting community parameters when compared to multispecies connectivity models. Incorporating multispecies connectivity showed more consistent effects for all community parameters, than single-species models, since the overlap between species' dispersal abilities in the landscape shows poor agreement. Habitat size and quality, though less important, were also determinant in explaining community parameters while possibly relating to the provision of suitable nesting and foraging conditions. Both habitat and landscape filters concur to govern community assembly, though likely influencing different processes: while landscape connectivity determines which species can reach a patch, habitat quality determines which species settle in the patch. Our results also suggest that surrogating multispecies connectivity from single species has potential to source bias by assuming species perceive landscape and its barriers similarly. Inference on this issue must be gathered from as much species as possible.
\end{abstract}

\section{Introduction}

The ongoing decline of biological diversity in present landscapes is mostly driven by the loss and fragmentation of habitats (Haddad et al., 2015). As landscapes change, natural or semi-natural habitat patches are increasingly scattered and isolated, with wildlife populations becoming increasingly disconnected in the remnant suitable patches.

Landscape connectivity relates to both the capacity of the landscape to hold viable routes for dispersal through an inhospitable matrix (structural connectivity, Calabrese and Fagan, 2004), and the ability of a species to engage in such dispersal movements (functional connectivity, Tischendorf and Fahrig, 2000). Enhancing and restoring landscape connectivity (Taylor et al., 1993) may facilitate dispersal movements (Haddad et al., 2003), the colonization of newly available patches (Haddad et al., 2015), and gene flow between populations (Whitlock et al., 2000), thus reducing the risk of local extinction (Gonzalez et al., 1998; Bennet et al., 2006; Staddon et al., 2010). Yet, the assessment of functional connectivity remains challenging (Correa Ayram et al., 2016)

\footnotetext{
* Corresponding author. UBC - Conservation Biology Lab, LabOr - Laboratory of Ornithology, Department of Biology, University of Évora, Mitra, 7002-554, Évora, Portugal.

E-mail addresses: pas@uevora.pt (P.A. Salgueiro), valerio.frank@gmail.com (F. Valerio), carmo.ms@gmail.com (C. Silva), amira@uevora.pt (A. Mira), jrabaca@ uevora.pt (J.E. Rabaça), smsantos@uevora.pt (S.M. Santos).
} 
if only to incorporate the movement ability of species, neglected in structural connectivity approaches. In particular, there is still limited insight on how landscape connectivity mediates local multispecies assemblages in highly fragmented landscapes (Ryberg and Fitzgerald, 2016; Fletcher et al., 2016).

Identifying the mechanisms governing multi-species assemblages may allow ecologists to understand the spatial and temporal variation of the diversity and composition of local communities (Cornell and Harrison, 2014). These mechanisms may be dependent on a set of habitat filters that operate locally selecting against certain species, thus determining the set of species likely to occur at a given patch. For birds, these features are often related with vegetation structure (e.g., Lindenmayer et al., 2012; Martin and Proulx, 2016; Salgueiro et al., 2018a), interspecific interactions (Klingbeil and Willig, 2016), or human disturbance (e.g., herbicide use, Kroll et al., 2017). However, landscape effects are expected to also play a relevant role in a context of high fragmentation or isolation (Fahrig, 2002; Antongiovanni and Metzger, 2005; Stouffer et al., 2006). Because landscapes offer different permeability to different species, local assemblages in isolated patches should vary according to species dispersal ability (Liu et al., 2018) and sensitivity to barriers (Breckheimer et al., 2014). If patches are highly connected for most species, we should expect higher species richness or diversity, as most species are able to reach those patches. Otherwise, landscape will filter out species for which the unsuitable matrix restricts their movements, and the number of species will be a subset of the regional pool of species. Yet, disentangling the effects of landscape connectivity from other key factors for species occurrence (e.g., habitat quality) is still lacking in literature (Fletcher et al., 2016).

Many studies on multispecies connectivity struggle with limitations and much of the evidence today is unclear (Frey-Ehrenbold et al., 2013; Kang et al., 2015), and mostly relying on indirect inference (Jønsson et al., 2016). For instance, studies often approach the structural connectivity of the landscape to measure how it shapes the spatial structure of metacommunities (e.g., Velázquez et al., 2019; Lindenmayer et al., 2020). Because these approaches solely lie on the spatial arrangement of habitat elements, they often assume that different species have the same ability to move between patches of suitable habitat, which offers a simplified and sometimes unrealistic view of the effects of connectivity.

In this study, we used a non-manipulative experimental design taking advantage of the patchiness of a landscape subjected to longstanding forestry activity. The main aim is to examine how functional connectivity determines the spatial distribution of a bird community inhabiting a fragmented landscape. We focus on a single, most scattered habitat and its distinctive bird community to test single- and multispecies connectivity models on species occurrence and community assemblage. By depicting patch size and habitat quality from all patches and mapping landscape attributes, we compare habitat attributes and landscape filtering effects on local communities (environment and dispersal filters, respectively, sensu Cadotte and Tucker, 2017). We expect that functional connectivity will be able to define species-specific dispersal abilities, thus proving effective predictors of spatial distribution for species. We hypothesize that local community composition and diversity will respond to the cumulative ability of the species (multispecies connectivity) to reach a patch (landscape filtering hypothesis). We test this hypothesis by comparing models accounting for multispecies connectivity and models retaining only single-species connectivity or neglecting this component. Overall, we discuss the effectiveness of multispecies connectivity over single-species approaches, as most species show different dispersal abilities or habitat requirements.

\section{Material and methods}

\subsection{Study area}

The study was carried out in Center-West Portugal (centroid: $39^{\circ} 38^{\prime} \mathrm{N} 9^{\circ} 02^{\prime} \mathrm{W}$ ), covering an area of 11,121 ha (Fig. 1 ). The landscape is dominated by standard production forest involving intensive forestry activities (e.g., logging, plantation, thinning, and understory management) of maritime pine (Pinus pinaster) and non-native plantations (Eucalyptus sp.). Each patch is managed under a rotational scheme of clear-cut patches where shrubs prevail (normally persisting for 5 years; $11.1 \%$ cover), newly planted forests subjected to regular thinning

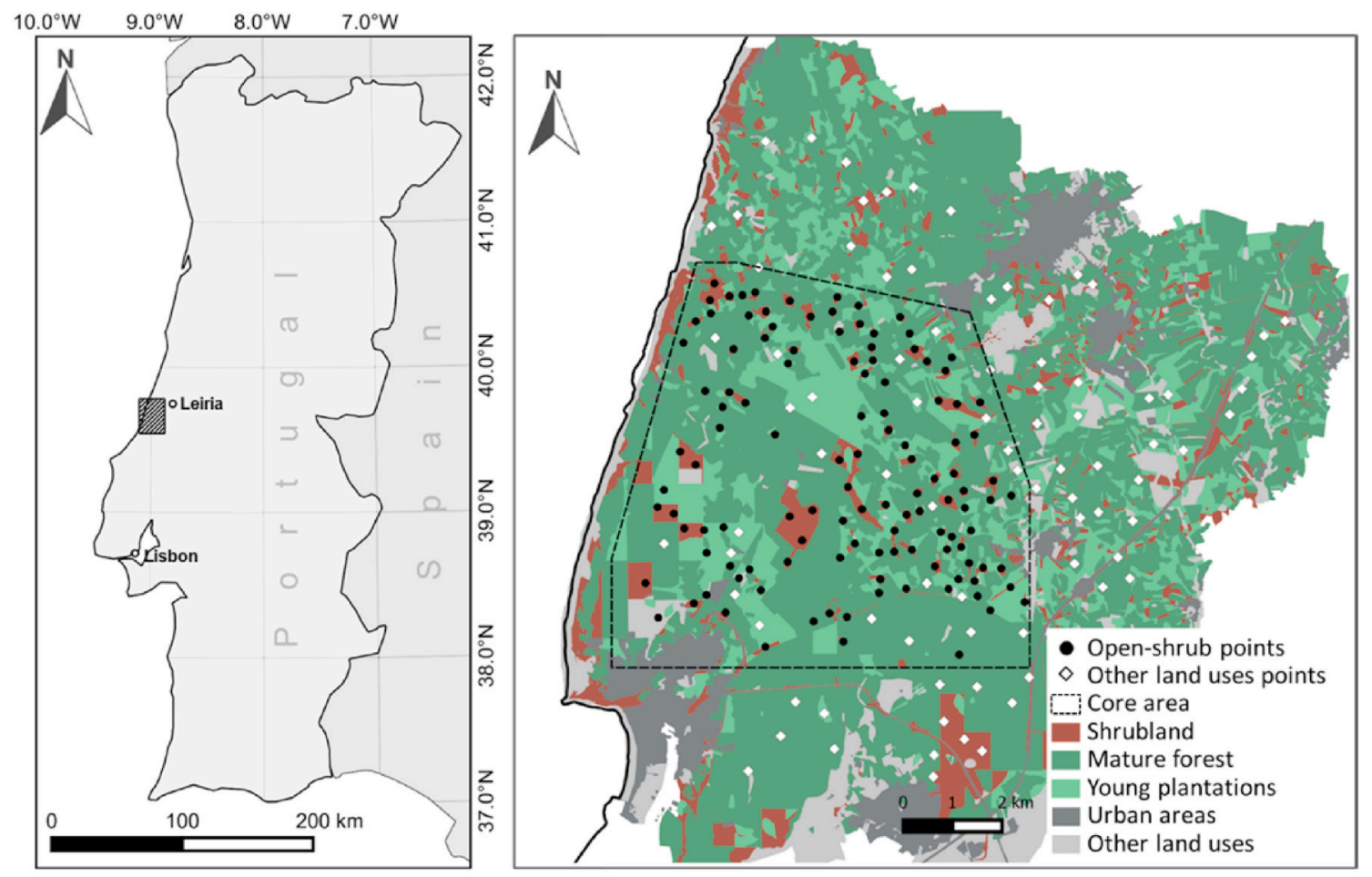

Fig. 1. Location and detailed land uses of the total and central study areas where open shrubland habitats are embedded in a forest dominated matrix. 
(18.0\% cover), and mature forests (with stands reaching 50-80 years for pines $-41.7 \%$ cover; and 9-10 years for eucalypts $-7.6 \%$ cover). This resulted in a heterogeneous landscape mosaic of well-defined even-aged stands, which vary in composition, density, and age. Because forest is the dominant land use in the landscape, open-shrub patches exhibit a scattered distribution embedded within the forest matrix (Fig. 1). Consequently, open-shrub patches are highly susceptible to fragmentation and isolation effects, presenting the ideal conditions to test for the effects of connectivity on species distribution. Furthermore, they sustain a specialized bird community confined to shrublands that may perceive forest as a barrier to dispersal due to visual obstruction (e.g., Prevedello et al., 2011). Consequently, bird species must rely mostly on habitat cues to engage in dispersion.

\subsection{Focal species surveys}

We focused our effort in sampling the shrubland bird community. Bird data was obtained through 10 min point counts (Bibby et al., 2000) with a distance limit of $100 \mathrm{~m}$. A total of 203 point counts were performed on the most representative land uses for the entire study area (Supplementary Material A), 120 of which covered every open-shrub patch (minimum patch size: $0.226 \mathrm{ha}$ ) located at the center of the study area (central area totaling 3500 ha, Fig. 1).

Sampling took place during the breeding season (between April and May 2014), when both resident and migratory species are more conspicuous. Surveys were carried out by one observer (PAS) during the period of highest detectability (6:00-11:00 a.m., Palmeirim and Rabaça, 1994) and with favorable weather conditions (Bibby et al., 2000). Bird abundance was gathered for each species seen or heard, but fly-over individuals were not included in the analysis.

We visited each survey point once to enhance the statistical power and representativeness of the study area (e.g., Loos et al., 2015). To avoid bias from false absences, we calculated the detectability by means of single visit occupancy models (Lele et al., 2012) using the package "detect" (Solymos et al., 2016) (see details in Supplementary Material A). After this procedure, we retained four bird species showing high detectability and representativeness in the study area for subsequent analyses: Linnet (Linaria cannabina), Stonechat (Saxicola rubicola), Dartford Warbler (Sylvia undata) and Wren (Troglodytes troglodytes).

\subsection{Environmental variables}

We used two types of environmental variables: (1) a set of spatially explicit landscape variables, and (2) a set of local vegetation structure and composition to assess habitat quality (see Supplementary Material B for a detailed description).

\subsubsection{Landscape variables}

Landscape variables relate to landscape composition and configuration metrics acquired from GIS software (version 2.2., Quantum GIS Development Team, 2013). A patch-based conceptualization was used since it provides a suitable and informative description of landscape attributes (Salgueiro et al., 2018b). We produced a thorough land use map (minimum patch size: $100 \mathrm{~m}^{2}$ ) using Bing Maps aerial photography (year: 2014; resolution: $30 \mathrm{~cm}$ ) with field ground validation. We extracted variables describing both landscape composition and configuration. Compositional parameters regarded the proportions of the main land uses (open shrubland, mature pine forest, non-native forest, and young plantations) and distance to other land uses (urban areas) or roads, and Shannon's landscape diversity index. Configuration patterns were determined by calculating the number of patches and edge length (considering different edge contrast between the vertical structure of the vegetation of adjacent patches; Ries et al., 2004). Each candidate variable (except for distances) was measured in two buffer widths centered around the point count $(100 \mathrm{~m}$ and $250 \mathrm{~m})$ to consider different spatial scales to which species may respond (Morelli et al.,
2013).

\subsubsection{Habitat quality}

We described habitat quality as the characteristics of the patch (patch size) and vegetation that relate with the provision of appropriate environmental conditions (sensu Mortelliti et al., 2010) for bird species to nest and forage. Density (cover) and structure (height and variation of height) of vegetation layers (shrubs and trees) were sampled from field measurements (see details in Supplementary Material B).

Additionally, we identified shrub and tree species occurring at each site, thus providing information on the composition of vegetation. We applied a hierarchical clustering technique weighing trait similarity among plant species using package "vegan" (Oksanen et al., 2017) to reduce the amount of plant species with similar traits into groups providing similar ecological functions to birds (Söderström et al., 2001) (Supplementary Material B). We estimated vegetation density by pooling together all species belonging to the same group, the most relevant being: Trees, Calluna-Erica heath shrublands, Thick thorny shrubs, Sand dunes shrubs.

\subsection{Functional connectivity modelling}

All modelling procedures were performed in $\mathrm{R}$ (version 3.0.2., $\mathrm{R}$ Development Core Team, 2013) unless stated otherwise.

\subsubsection{Species distribution models}

We built spatially explicit, functional connectivity models for each species based on circuit theory (McRae et al., 2008). We relied on species distribution models (SDM) to infer landscape permeability. This approach has been proved to perform well as a cost-effective method to build functional connectivity models when data on movement or dispersal ability is lacking (Keeley et al., 2016; Ahmadi et al., 2017; Valerio et al., 2019).

For SDM, we modelled the occurrence (presence/absence) of each of the four focal species in response to the set of spatially explicit landscape variables (GLM with binomial error distribution, logistic link function) for the entire study area. All variables were standardized (mean of 0 and standard deviation of 1), in order to reduce the order of magnitude between them and have comparable regression coefficients. Each variable fit was initially screened individually (univariated models) while considering the linear and quadratic predictor for each of the two buffer distances. We also evaluated interactions between shrub understory height and main land uses, since we expected that responses would change according to understory's vertical structure. Variables were selected for the most parsimonious model (lowest AICc) following a stepwise selection approach using MASS library (Venables and Ripley, 2002). The model ran on a training subset of data (66\%), and was tested on the remaining subset. The area under the curve (AUC) was calculated in the testing subset for model validation. We repeated this procedure 100 times, and averaged the results (coefficients) of all models. All four species showed a close relation to shrubland habitats, as we found positive responses of the species to either shrub cover or height (see Supplementary Material D). The spatially explicit SDM (10 m resolution) was the interpolation of the averaged predicted values for the entire landscape.

All models revealed a reasonably high ability to predict species occurrence $\left(\mathrm{AUC}_{\text {Linnet }}=0.86 \pm 0.06\right.$; $\mathrm{AUC}_{\text {Stonechat }}=0.84 \pm 0.05$; $\mathrm{AUC}_{\mathrm{DWarbler}}=0.82 \pm 0.04 ; \mathrm{AUC}_{\mathrm{Wren}}=0.74 \pm 0.04$ ), indicating that selected variables were good predictors in describing potential suitable areas for each species.

\subsubsection{Landscape resistance estimation}

Landscape resistance (the degree to which a landscape restricts movements) was computed as an inverse linear function of predicted probability of occurrence. However, because such approaches are generally too conservative and species tend to be less demanding 
regarding habitat requirements when dispersing, we additionally considered two negative exponential functions to transform SDM into a resistance matrix, following Trainor et al. (2013):

$R=100-99 * \frac{1-e^{-c^{*} H}}{1-e^{-c}}$

The resistance $(\mathrm{R})$ is an exponential transformation of the predicted probability of occurrence from the spatially explicit SDM $(\mathrm{H})$ determined by a factor $(c)$ which defines the non-linearity of the relation between resistance and habitat suitability. As $c$ increases, the steepness of the curve increases, meaning that resistance is lower at low suitability values. We generated three resistance surfaces for each species, using three transformation values: $c=0.25$ for a linear inverse proportion, $c=$ 2 for a slight non-linear relation, and $c=8$ for a steeper non-linear relation (e.g. Valerio et al., 2019).

\subsubsection{Modelling procedure}

We created dispersal models based on circuit theory, which represents animal movement in the form of an electrical network (McRae et al., 2008) by simulating multiple pathways for movement between nodes over a resistance surface.

For connectivity modelling purposes, we defined the nodes independently from our samples by extracting patches from the SDM with high probability of occurrence. This avoided high estimates of connectivity around point samples, which could bias our results. We initially determined the cut-off point by looking for the threshold that maximized the percentage of correct classifications (presence/absence) (Manel et al., 2001; Liu et al., 2005). We then extracted the core areas - high quality habitat patches, excluding patches greatly subjected to edge effects due to their shape (e.g. elongated patches; Lindenmayer, 1994). We followed Puddu and Maiorano (2016) on these calculations by operating a Morphological Spatial Pattern Analysis on the cutoff map in the Guidos software (Vogt, 2016). The resulting habitat patches were transformed into centroids while retaining the patch size attribute. Minimum patch size was set as the minimum area needed to hold a bird's territory (see Supplementary Material C).

Before connectivity modelling, we filtered the number of possible node interactions to reduce overestimation of connectivity by neglecting unlikely links. We inferred functional distances constrained by each of the resistance matrices using the package "gdistance" (van Etten, 2017) and used them to calculate the probability of connectivity (PC, Saura and Pascual-Hortal, 2007) between all pairs of nodes using the 'distance' parametrization in the Conefor software (version 2.2, Saura and Torné, 2009). Node location weighed by its size, and median distance of dispersal of each bird species (Supplementary Material C) were used as set-ups for the calculation of PC. All pairwise nodes showing PC $\geq 0.5$ were considered connected, i.e., we assumed that a node was reachable from its pair. All remaining links $(\mathrm{PC}<0.5)$ were discarded from further analysis.

Finally, to map species-specific functional connectivity we used the Gflow software (version 0.1.7, Leonard et al., 2016). Current was set to flow between each pair of connected nodes, while weighing the conductance (the inverse of resistance matrices). After the combinations of likely connected nodes were calculated, current density was summed into a single cumulative map representing the probability of successful dispersal of an organism (McRae et al., 2008; Koen et al., 2014). This procedure was performed for each of the four focal species times the three resistance matrices (exponential functions), leading to 12 functional connectivity models.

\subsection{Data analysis}

Firstly, we compared the effectiveness of the three functional connectivity models (FCM) accounting for each scenario of resistance $(c)$ in explaining each species distribution. We used bird abundance data gathered from open-shrub patches within the central area (Fig. 1) of the modelling range, thus avoiding several misconceptions of landscape connectivity occurring at the limits of study areas (Koen et al., 2010; Liu et al., 2018). We performed GLMs (Poisson error distribution, log link function) to determine the effects of each functional connectivity scenario on bird abundance, in comparison with habitat quality descriptors. Four models were obtained for each of the four focal species, one just composed of habitat quality descriptors selected through a univariated modelling approach, and three others additionally holding a functional connectivity scenario for each considered $c$ (see Eq. (1)). For each species, we compared AIC, explained deviance and r-squared values to assess the fit of the models and determined which scenario improved the model ability to predict bird abundance. Additionally, we calculated the relative importance of each variable through a model averaging approach (Burnham and Anderson, 2002).

Afterwards, we determined if connectivity would influence shrubland bird community-level parameters by testing its effects on species richness, overall abundance, dominance of the most abundant species (1st ranked), and Simpson's diversity considering the entire shrubland community. The effectiveness of single- and multispecies connectivity models was tested for each case using GLM (Poisson error distribution for the first two, and Gaussian for both the later). Single-species connectivity models consisted on the best resistance scenarios selected from the previous species-specific analyses. Multispecies connectivity model was defined as the joint cost of shrubland bird species to cross a cell, obtained by averaging the values of the best single-species connectivity scenarios (the values were normalized to confer the same weight regardless of the species). We also tested the influence of the coefficient of variation between all four connectivity models to check the effects of uneven values on community parameters. Lower values indicate that all four species perceived a given cell with the same cost; otherwise, the cells offered different resistance. We used the same modelling procedure and analyzed the same parameters as for single species models.

We further examined if species showed similar dispersal abilities by overlapping connectivity models. For two species sharing similar dispersal abilities, a higher probability of having overlaid conductance paths is expected, and thus a higher proportion of spatial overlap. We measured spatial overlap firstly by calculating the correlation between overlaying pairs of cells of the single-species, spatially explicit functional connectivity model (our proxy for dispersal ability, Jacobson and Peres-Neto, 2010) using Pearson correlation coefficients. Secondly, we determined the spatial overlap by calculating the proportion of area (cells) shared by two species in relation to the total amount of area covered by both species, above a given conductance threshold. We have only considered cells above the normalized 0.5 value for the multispecies functional connectivity model. We compared the observed spatial overlap coefficient for each pair of species with a set of 100 random permutations of the data, ranging the conductance threshold between 0.2 and 1 (the lower and higher species-specific normalized values of conductance for all species). If two species agree on the same locations for dispersal at a given threshold, then the observed spatial overlap will be above the expected random simulations, and species show synergistic relation (Breckheimer et al., 2014). Otherwise, species may show conflicting dispersal ability, i.e., the dispersal routes for one species do not fit the other and observed overlap will be below the expected. If spatial overlap is the same as random, then both species show an independent relation.

\section{Results}

\subsection{Connectivity effects on single-species distribution}

In eleven out of twelve models, the inclusion of functional connectivity improved its ability to predict the occurrence of each of the four shrubland bird species, regardless of the exponential function used to describe it (Table 1). Nevertheless, the magnitude of exponential transformation weighed differently for some species. For Stonechat and 
Table 1

Parameter estimates used to evaluate the fit of species abundance models (Akaike's information criterion - AIC, and respective variation - $\triangle \mathrm{AIC}$; proportion of explained deviance - ExpDev; and r-squared value - Rsq). Four models were tested, one composed of habitat quality descriptors, and three other additionally with functional connectivity models (FCM) for each scenario of resistance (c).

\begin{tabular}{lllll}
\hline $\begin{array}{l}\text { Model } \\
\text { parameters }\end{array}$ & Habitat & $\begin{array}{l}\text { Habitat }+ \text { FCM } \\
(\mathrm{c}=0.25)\end{array}$ & $\begin{array}{l}\text { Habitat }+ \text { FCM } \\
(\mathrm{c}=2)\end{array}$ & $\begin{array}{l}\text { Habitat }+ \text { FCM } \\
(\mathrm{c}=8)\end{array}$ \\
\hline Linnet & & & & \\
AIC & 175.130 & 157.84 & $\mathbf{1 5 7 . 5 6 0}$ & 166.38 \\
$\Delta$ AIC & 17.570 & 0.280 & $\mathbf{0 . 0 0 0}$ & 8.820 \\
ExpDev & 0.159 & 0.310 & $\mathbf{0 . 3 1 2}$ & 0.243 \\
Rsq & 0.101 & 0.300 & $\mathbf{0 . 3 0 6}$ & 0.157 \\
Stonechat & & & & \\
AIC & 170.350 & $\mathbf{1 5 5 . 4 6 0}$ & 155.560 & 156.650 \\
$\Delta$ AIC & 14.890 & $\mathbf{0 . 0 0 0}$ & 0.100 & 1.190 \\
ExpDev & 0.230 & $\mathbf{0 . 3 7 0}$ & 0.370 & 0.370 \\
Rsq & 0.188 & $\mathbf{0 . 2 9 6}$ & 0.279 & 0.255 \\
Dartford Warbler & & & & \\
AIC & 234.61 & 229.99 & $\mathbf{2 2 8 . 8 1}$ & 233.2 \\
AAIC & 5.800 & 1.180 & $\mathbf{0 . 0 0 0}$ & 4.390 \\
ExpDev & 0.379 & 0.432 & $\mathbf{0 . 4 4 2}$ & 0.406 \\
Rsq & 0.382 & 0.462 & $\mathbf{0 . 4 7 5}$ & 0.413 \\
Wren & & & & \\
AIC & 258.090 & $\mathbf{2 5 0 . 7 5 0}$ & 251.400 & 258.41 \\
$\Delta$ AIC & 7.340 & $\mathbf{0 . 0 0 0}$ & 0.650 & 7.660 \\
ExpDev & 0.115 & $\mathbf{0 . 2 0 0}$ & 0.194 & 0.130 \\
Rsq & 0.151 & $\mathbf{0 . 2 5 6}$ & 0.238 & 0.162 \\
(2000 & & & &
\end{tabular}

Values in bold signal the best model.

Wren, functional connectivity based on a resistance matrix with a linear inverse proportion $(c=0.25)$ provided the best-fitted results, while for Linnet and Dartford Warbler, a slight non-linear relation $(c=2)$ offered a better outcome. Steeper non-linear relations $(c=8)$ consistently provided lower fit and less parsimonious models with $\triangle$ AIC $>4$ for all species. Among the most conservative approaches $(\mathrm{c}=0.25$ and $\mathrm{c}=2$ ) only minor differences were detected ( $\triangle \mathrm{AIC}<2$ for all species), either providing good alternatives as the best model.

Bird species response to functional connectivity (FCM) was unequivocally positive in all cases (Fig. 2). This was the only variable present at all single species models, and it also revealed high relative importance as well (mean RVI $=0.99$, see Supplementary Material E for detailed results on model estimates).
Other variables included in the models regarded specific requirements of the species. Patch size was relevant for all species, except Wren for which no effect was detected. All other species' abundance increased with increasing patch size. Regarding habitat quality, Stonechats were more likely to occur in patches with lower shrub heights, but also in areas with tall shrubs if shrub height was heterogeneous (interaction between ShrbHeight and ShrbHeightCV). Dartford Warbler, however, was more abundant in patches with homogeneous shrub height. Shrub cover (either as a single factor or in interaction) showed a positive, but equivocal, relation to Dartford Warbler and Wren abundances. Linnet did not show any particular relation to the structure of the shrub layer, being related mostly to its composition. Shrub patches dominated by Calluna/Erica (HeathShrb) and species typical dune vegetation (DuneShrb) tended to have negative effects on Linnet abundance. Nevertheless, this species was positively favored when thick, thorny shrubs prevailed (ThornyShrb, namely Genista, Stauracanthus, and Ulex species). In fact, the positive effects of this group of plants extended to other species such as the Wren and Dartford Warbler.

\subsection{Connectivity effects on community assemblages}

Adding multispecies functional connectivity to habitat-only models improved the ability to predict total abundance, species richness, 1st rank dominance and Simpson's diversity values (Table 2). Single-species functional connectivity rarely provided competing alternatives to the multispecies approach, as single models consistently produced higher AIC values ( $\triangle$ AIC $>4$ in most cases), and lower fit. Stonechat and Linnet showed the best results among single-species functional connectivity, even though its influence was not consistent for all parameters: while Stonechat functional connectivity could compete as an alternative for multispecies connectivity model for total abundance, Linnet outperforms in all other parameters. Both Dartford Warbler and Wren functional connectivity were poor predictors, lowering the fit of the model, in some cases to similar levels as the habitat-only model.

Multispecies functional connectivity (FCM) showed consistent results for all parameters (Fig. 3), exhibiting unequivocal positive effects on total abundance, species richness (Fig. 4) and Simpson's diversity. Concurrently, it also revealed a negative effect on 1st rank dominance. The coefficient of variation of the single-species functional connectivity models (FCM_cv) signaling the discrepancy of conductance between species, was only selected in the total abundance model, but with an

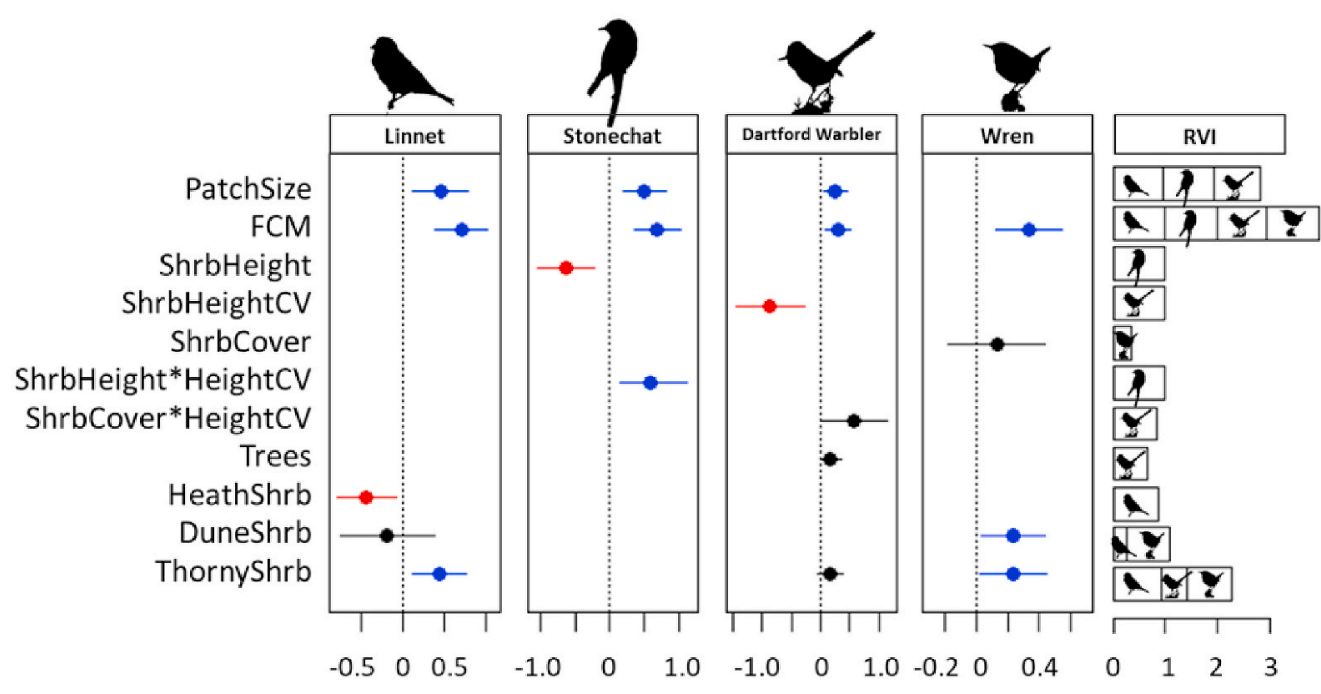

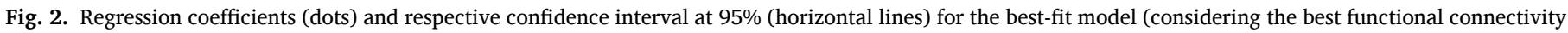

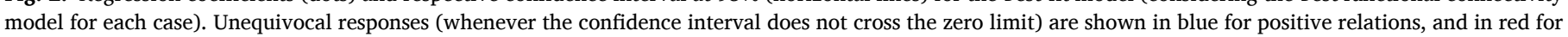

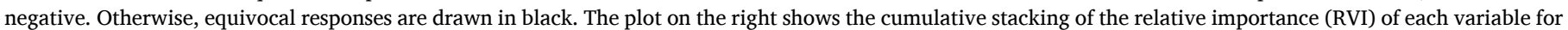
each of the species. (For interpretation of the references to colour in this figure legend, the reader is referred to the Web version of this article.) 
Table 2

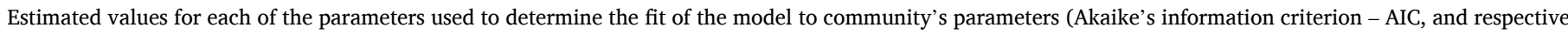
variation $-\triangle \mathrm{AIC}$; proportion of explained deviance - ExpDev; and r-squared value - Rsq).

\begin{tabular}{|c|c|c|c|c|c|c|}
\hline Model Parameters & Habitat & Habitat $+\mathrm{FCM}_{\text {Linnet }}$ & Habitat + FCM $_{\text {Stonechat }}$ & Habitat + FCM $_{\text {D.Warbler }}$ & Habitat + FCM $_{\text {Wren }}$ & Habitat + FCM $_{\text {Multispecies }}$ \\
\hline \multicolumn{7}{|l|}{ Total abundance } \\
\hline AIC & 419.70 & 408.65 & 406.82 & 413.12 & 420.78 & 403.88 \\
\hline$\Delta \mathrm{AIC}$ & 15.82 & 4.77 & 2.94 & 9.24 & 16.90 & 0.00 \\
\hline ExpDev & 0.209 & 0.308 & 0.321 & 0.274 & 0.216 & 0.359 \\
\hline Rsq & 0.203 & 0.308 & 0.317 & 0.274 & 0.206 & 0.360 \\
\hline \multicolumn{7}{|l|}{ Species richness } \\
\hline AIC & 342.72 & 335.76 & 337.21 & 338.58 & 344.23 & 333.34 \\
\hline$\Delta \mathrm{AIC}$ & 9.38 & 2.42 & 3.87 & 5.24 & 10.89 & 0.00 \\
\hline ExpDev & 0.153 & 0.293 & 0.270 & 0.249 & 0.161 & 0.331 \\
\hline Rsq & 0.154 & 0.305 & 0.272 & 0.253 & 0.157 & 0.339 \\
\hline \multicolumn{7}{|l|}{ 1st rank dominance } \\
\hline AIC & 16.64 & 8.72 & 10.42 & 15.17 & 13.68 & 5.53 \\
\hline$\Delta \mathrm{AIC}$ & 11.11 & 3.19 & 4.89 & 9.64 & 8.16 & 0.00 \\
\hline ExpDev & 0.102 & 0.183 & 0.169 & 0.131 & 0.144 & 0.207 \\
\hline Rsq & 0.102 & 0.183 & 0.169 & 0.131 & 0.144 & 0.207 \\
\hline \multicolumn{7}{|l|}{ Simpson's diversity } \\
\hline AIC & 32.91 & 26.83 & 27.20 & 31.86 & 30.64 & 23.33 \\
\hline$\Delta \mathrm{AIC}$ & 9.59 & 3.51 & 3.88 & 8.53 & 7.31 & 0.00 \\
\hline ExpDev & 0.148 & 0.210 & 0.207 & 0.172 & 0.181 & 0.235 \\
\hline Rsq & 0.148 & 0.210 & 0.207 & 0.172 & 0.181 & 0.235 \\
\hline
\end{tabular}

Values in bold signal the best model.

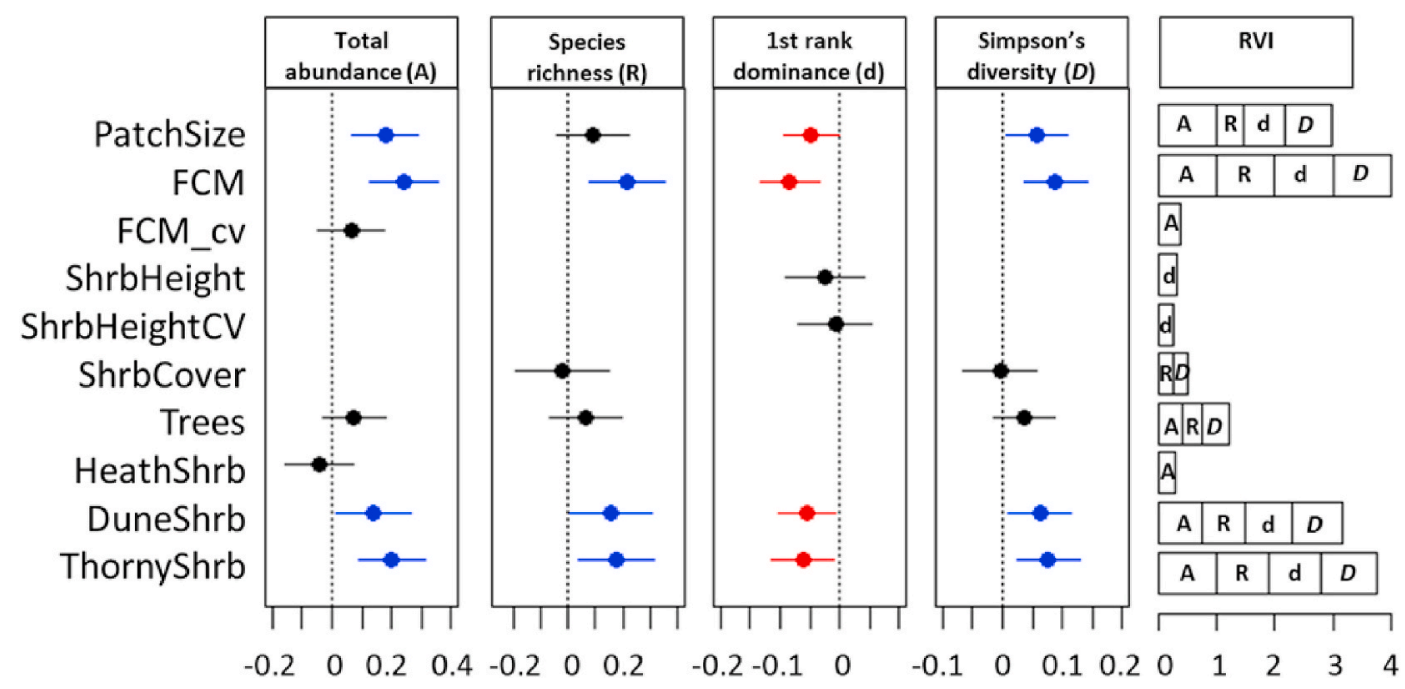

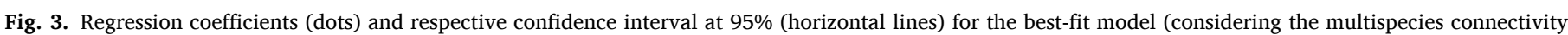

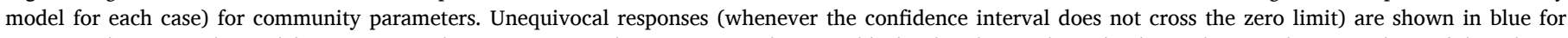

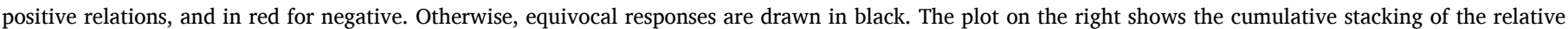

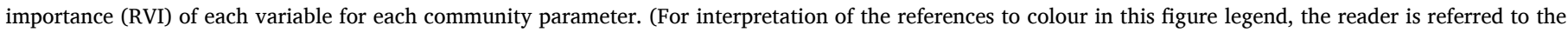
Web version of this article.)

equivocal meaning and a poor predictive power. The abundance of dune (DuneShrb) and thorny shrubs (ThornyShrb) were also consistent between parameters, revealing the same trends as functional connectivity. However, functional connectivity singled out as the most important variable (RVI $=1.00$ in all parameters, Supplementary Material F) while dune shrubs exhibited lower importance (RVI ranged between 0.73 and 0.85 ) and thorny shrubs showed less consistent values (RVI $=[0.87$, 1.00]). The amount of habitat (PatchArea) was also an important feature $(\mathrm{RVI}=[0.46,1.00])$ explaining community parameters, though it showed inconsistency for species richness.

All other variables related to shrub structure (height, heterogeneity and cover) and composition (abundance of trees and Calluna/Erica heath species) showed equivocal (near-zero) effects. Accordingly, their relative importance for the models was modest, overall ranging between 0.24 and 0.46 .

\subsection{Species spatial overlap}

While comparing dispersal abilities between pairs of species (Fig. 4), we found that results varied between moderate $\left(r_{s}=0.62\right.$ between Linnet and Stonechat; and $r_{s}=0.60$ between Dartford Warbler and Wren) and weak correlations $\left(r_{s}=0.24\right.$ and 0.34 between Wren and both Linnet and Stonechat, respectively). The proportion of spatial overlap also showed poor agreement between dispersal abilities of the species in some cases (Fig. 5). Wren, for instance, differs from Linnet and Stonechat dispersal abilities, because the observed agreement between their conductances is lower than expected. Dispersal abilities of these species were, therefore, conflicting. Dartford Warbler observed proportion of spatial overlap did not differ greatly from randomized simulations. Yet, Linnet and Stonechat agreed between them, so there is a high chance that cells with high conductance may serve both species. In fact, both species dispersal ability overlap in $50 \%$ when considering a threshold of conductance $=0.50$. At the same threshold, these species 


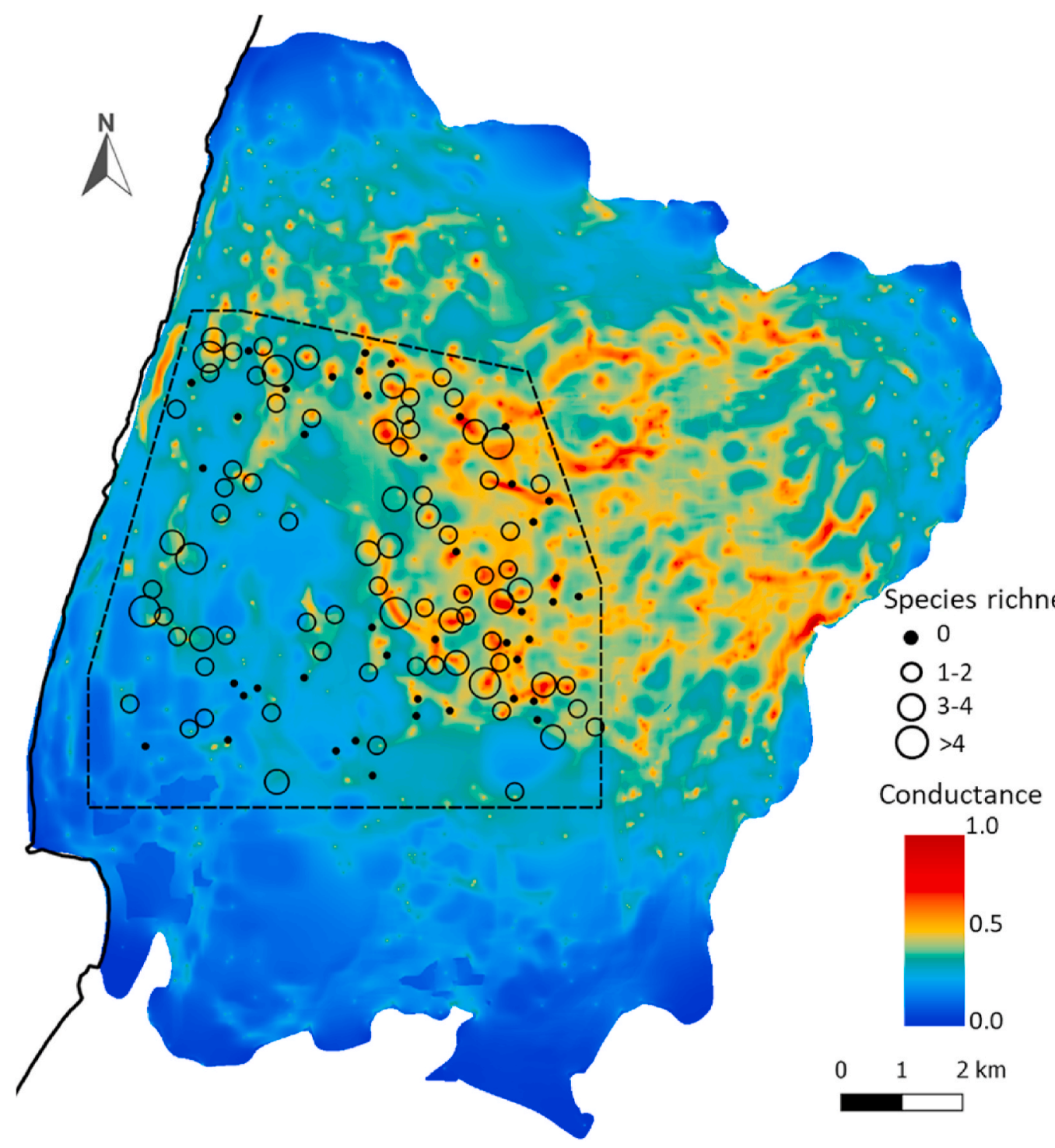

Fig. 4. Multispecies functional connectivity model: red shading signal the areas of higher connectivity for all species, while blue shading mark areas of greater resistance to movement. Circles signal richness levels along the sampled shrub patches within the central area (delimited by a dashed line). (For interpretation of the references to colour in this figure legend, the reader is referred to the Web version of this article.)

overlapped ca. $40 \%$ with Dartford Warbler's dispersal ability and a modest $20-30 \%$ with Wren.

\section{Discussion}

Our results clearly show that multispecies functional connectivity had a strong and positive effect on local community diversity supporting the importance of landscape filtering structuring shrub bird community. Highly connected patches held richer and more diverse communities as hypothesized and in line with most of the evidence (Fletcher et al., 2016). It is likely that landscape connectivity allows birds to move and colonize other suitable patches supporting larger populations and diverse communities (Martensen et al., 2008). Conversely, isolated patches held less species possibly because low connectivity hinders individuals to move freely within the matrix. Therefore, they were more likely to be dominated by one or few species for which landscape matrix is more permeable. Most importantly, we found the landscape filtering effect to be very consistent and quite relevant when compared with other measures of patch size and habitat quality, largely accounted as utterly important for metacommunity structure (e.g., Ryberg and Fitzgerald, 2016; Lindenmayer et al., 2020).
However, this does not hinder that habitat filtering still plays a significant role in shaping local communities in our landscape. In fact, we also detected similar (though slightly smaller) effects of patch size: more diverse communities occurred in larger patches. The response was not conclusive for species richness, though a tendency for larger patches to hold more species is observable as predicted by the species-areas relationships theory (Arrhenius, 1921). In a reduced bird community like this, it is conceivable that even small patches can hold most of the species, but this effect may likely relate to the fact that effective patch size may not be restricted to the patch itself, but to the overall network of functionally connected patches (Martensen et al., 2008). Thus, connectivity complements habitat amount, mitigating possible effects derived from small patch size (the fragmentation threshold hypothesis, Fahrig, 2003).

Regarding habitat quality, local bird communities tended to be richer and diverse in patches where dune and thorny shrubs were more abundant. This may be related to the provision of suitable nesting and foraging conditions. For example, concealing nests in thorny or thick shrubs may offer additional protection from nest predation. This relation has been described for other bird communities (Söderström et al., 2001) or species (Svendsen et al., 2015), and was further observed in this study 

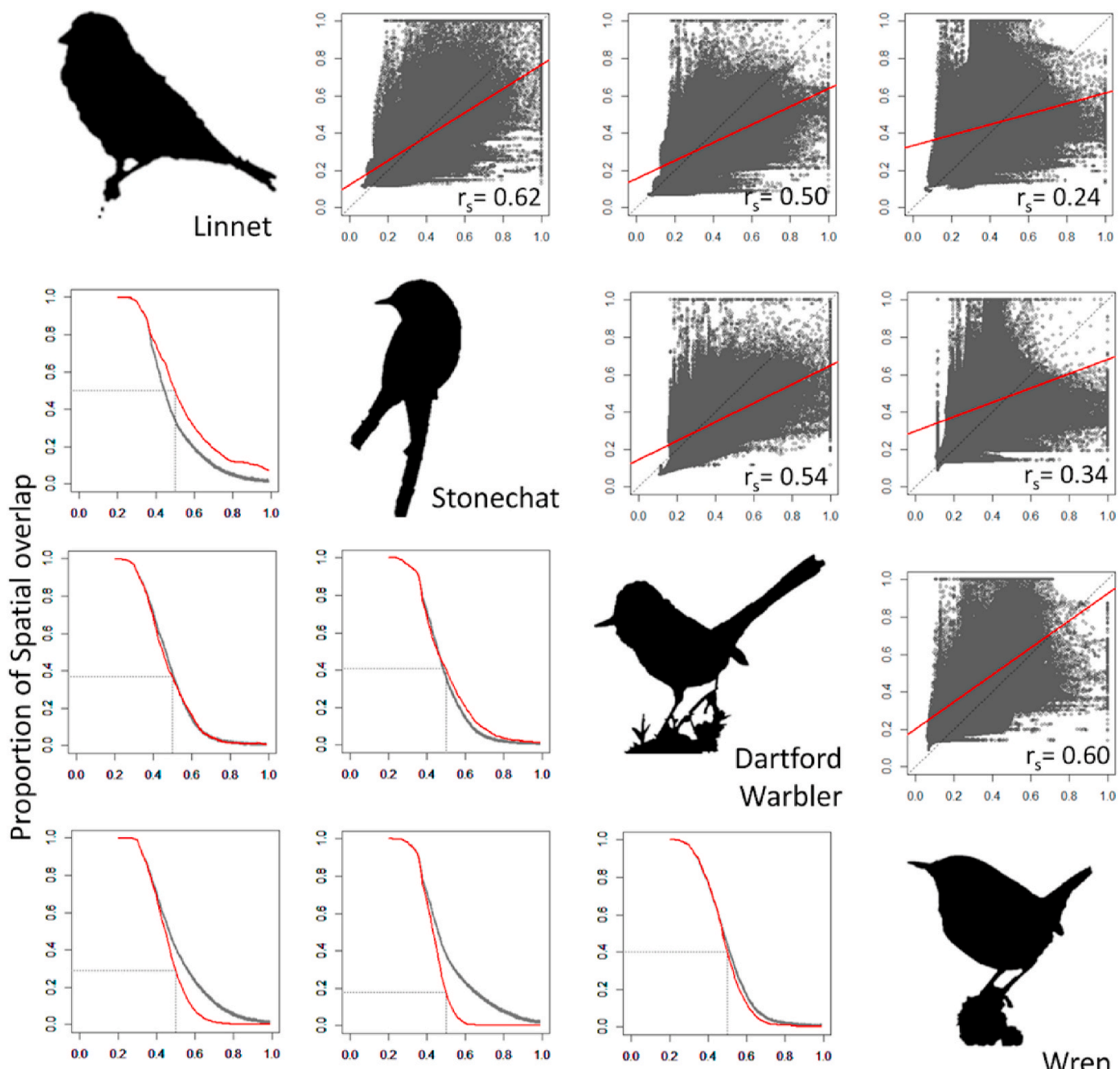

\section{Threshold of conductance}

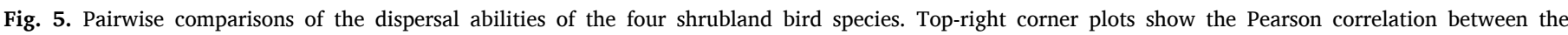

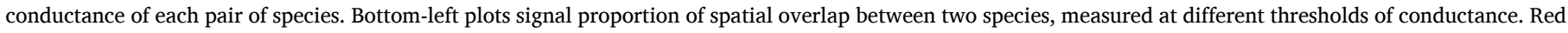

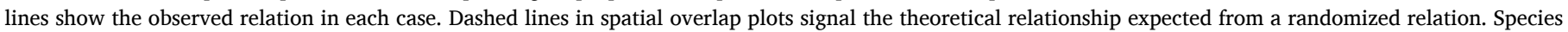
show synergistic relation when the red line is above the expected; otherwise, species show conflicting dispersal ability.

for species usually nesting in such conditions (Linnet, Dartford Warbler and Wren). Conversely, this relation was not detected in ground-nesting species (Stonechat) (Catry et al., 2010; de Juana and Garcia, 2015). Other dune shrubs (e.g., Corema album) often provide edible berries, an alternative resource even for mainly insectivorous birds.

Our results also show that despite all four species are sympatric each exploits its niche in different ways. For instance, Linnet is quite adverse to forested areas, while Wren is more tolerant as it also occurs in young pine plantations (Supplementary Material D). Stonechats usually nest and forage on the ground, thus avoiding patches with tall shrubs, whereas Dartford Warbler uses dense and thick shrubs for nesting (Catry et al., 2010). This could explain the modest overlap between single-species functional connectivity routes. One may argue that using SDM to build resistance surfaces will mostly reflect the occupied niche of each species and may not conveniently capture dispersal habitat characteristics (Revilla and Wiegand, 2008; Vasudev et al., 2015), even though we compensated for such effects by testing several negative exponential transformations.

\subsection{Theoretical implications}

Our study provides evidence that community assembly is largely dependent on both landscape connectivity and habitat quality. Both these attributes, however, are likely to influence different processes of the bird assembly (Lindenmayer et al., 2020). While landscape connectivity determines which species are able to reach a patch (colonization), habitat quality determines which species are expected to settle in that patch (occupancy). Thus, the weight that each of these attributes assumes on community assembly will strongly depend on the intrinsic dispersal ability of each species to move across the landscape (functional connectivity), as well as on the capacity of the patch to provide specific resources for the settlement of different species. For instance, while working with mobile species in highly connected landscapes, all of them will have the same ability to reach a patch. Because landscape will not offer enough resistance to filter species, it is unlikely that landscape connectivity will play a significant role in structuring local communities (Poniatowski et al., 2016). The same may hold true for impermeable matrices where all species are filtered and only habitat characteristics 
will determine which species occur. Conversely, as species exhibit specific requirements while traversing the matrix, the likelihood of each species reaching a patch differs as landscape offers uneven resistance. In this study, as landscape matrix filtered out species with lower capability to reach a suitable patch, the composition of local communities was highly dependent on landscape connectivity.

In this context, endorsing one focal or umbrella species to represent an entire community (i.e., assume multiple species perceive landscape and its barriers similarly; e.g., Cushman and Landguth, 2012) will hold potential bias, though may seem a cost-efficient solution (but see Dilkina et al., 2016 for budget trade-offs in designing corridors for single species) when empirical data on movement is lacking (Fagan and Calabrese, 2006; Jønsson et al., 2016). Functional connectivity is species-specific (Goodwin, 2003; Jacobson and Peres-Neto, 2010) and a suitable dispersal habitat/corridor for one species may not favor others (Koen et al., 2014; Wang et al., 2018). Our study supports the rationale that umbrella or focal species' connectivity is a poor proxy of multiple species landscape connectivity (McClure et al., 2016; Wang et al., 2018). Although some approaches show compelling evidence on the use of umbrella species, our general recommendation is that approaches dealing with communities should not rely only on measuring and enforcing connectivity for a single species (see also McClure et al., 2016), but rather gather inference from as much species as possible.

\subsection{Management implications}

Many studies devoted to understand patterns of biodiversity in fragmented landscapes are performed under controlled conditions, using manipulated landscapes (e.g., Ferraz et al., 2007; Haddad et al., 2015; Damschen et al., 2019), while this investigation draws evidence from real-world landscapes. For that reason, our results provide important recommendations for management of production forests (e.g., Viljur and Teder, 2018).

On-the-ground management practices should compromise with both landscape and habitat effects. Habitat conditions should relate to the specific requirements of the species, mainly those related with the provision of nesting/shelter and foraging conditions. In our case, shrubland birds benefited from thick thorny shrubs such as Genista triacanthos or Ulex sp. on which they may rely for nesting. Larger patches can hold higher levels of diversity and forest managers should promote them instead of smaller patches, thus avoiding small-estate management. Nevertheless, even smaller patches can hold significant amounts of diversity if properly connected to other suitable patches.

Our landscape is quite dynamic since patches are under a rotational scheme between short fallow periods where shrubs dominate, and elongated periods of forest stand (up to 80 years). This will likely affect functional connectivity patterns between years by changing landscape structure and, concomitantly, the ability of a species to engage and succeed in dispersion movements. For example, our data shows a spatially uneven distribution of connectivity that perhaps could change by adopting different management practices locally. Because connectivity can be a key factor for the persistence of animal communities, creating and managing long-lasting shrub corridors that compartmentalize landscape should allow the dispersal of species into newly available areas as source patches evolve into forest stands. As a positive side effect, this could also create discontinuities in the landscape that may prevent the control of forest threats such as summer fires.

\section{Declaration of competing interest}

The authors declare that they have no known competing financial interests or personal relationships that could have appeared to influence the work reported in this paper.

\section{Acknowledgements}

PAS, SMS and FV were funded by grants of the Portuguese Science Foundation (reference SFRH/BD/87177/2012, SFRH/BPD/70124/ 2010 and SFRH/BD/122854/2016, respectively). Fieldwork was kindly supported by SECIL - Companhia Geral de Cal e Cimento, S.A.

\section{Appendix A. Supplementary data}

Supplementary data to this article can be found online at https://doi. org/10.1016/j.jenvman.2021.112066.

\section{Author contributions}

Pedro A Salgueiro: Conceptualization, Investigation, Formal analysis, Writing - original draft; Francesco Valerio: Investigation, Formal analysis, Writing - review \& editing; Carmo Silva: Investigation; António Mira: Conceptualization, Resources, Supervision, Writing - review \& editing; João E Rabaça: Conceptualization, Supervision, Writing - review \& editing; Sara M Santos: Conceptualization, Supervision, Writing - review \& editing.

\section{References}

Ahmadi, M., Balouchi, B.N., Jowkar, H., Hemami, M.R., Fadakar, D., Malakouti-Khah, S., Ostrowsk, S., 2017. Combining landscape suitability and habitat connectivity to conserve the last surviving population of cheetah in Asia. Divers. Distrib. 23, 592-603. https://doi.org/10.1111/ddi.12560.

Antongiovanni, M., Metzger, J.P., 2005. Influence of matrix habitats on the occurrence of insectivorous bird species in Amazonian forest fragments. Biol. Conserv. 122 (3), 441-451. https://doi.org/10.1016/j.biocon.2004.09.005.

Arrhenius, O., 1921. Species and area. J. Ecol. 9 (1), 95-99.

Bennett, A.F., Radford, J.Q., Haslem, A., 2006. Properties of land mosaics: implications for nature conservation in agricultural environments. Biol. Conserv. 133 (2), 250-264. https://doi.org/10.1016/j.biocon.2006.06.008.

Bibby, C., Burgess, N., Hill, D., Mustoe, S.H., 2000. Bird Census Techniques, second ed. Academic Press.

Breckheimer, I., Haddad, N., Morris, W., Trainor, A., Fields, W., Jobe, R., Hudgens, B., Moody, A., Walters, J., 2014. Defining and evaluating the umbrella species concept for conserving and restoring landscape connectivity. Conserv. Biol. 28 (6), 1584-1593. https://doi.org/10.1111/cobi.12362.

Burnham, K.P., Anderson, D.R., 2002. Model Selection and Multimodel Inference: a Practical Information-Theoretic Approach, second ed. Springer, New York.

Calabrese, J.M., Fagan, W.F., 2004. A comparison-shopper's guide to connectivity metrics. Front. Ecol. Environ. 2 (10), 529-536. https://doi.org/10.1890/1540-9295 (2004)002[0529:ACGTCM]2.0.CO;2.

Catry, P., Costa, H., Elias, G., Matias, R., 2010. Aves de Portugal, Ornitologia do território continental. Assírio \& Alvim, Lisboa.

Cornell, H.V., Harrison, S.P., 2014. What are species pools and when are they important? Annu. Rev. Ecol. Evol. Systemat. 45 (1), 45-67. https://doi.org/10.1146/annurevecolsys-120213-091759.

Correa Ayram, C.A., Mendoza, M.E., Etter, A., Salicrup, D.R.P., 2016. Habitat connectivity in biodiversity conservation: a review of recent studies and applications. Prog. Phys. Geogr. 40 (1), 7-37. https://doi.org/10.1177/ 0309133315598713.

Cushman, S.A., Landguth, E.L., 2012. Multi-taxa population connectivity in the northern rocky mountains. Ecol. Model. 231, 101-112. https://doi.org/10.1016/j. ecolmodel.2012.02.011.

Damschen, E.I., Brudvig, L.A., Burt, M.A., Fletcher, R.J., Haddad, N.M., Levey, N.M., Orrock, J.L., Resasco, J., Tewksbury, J.J., 2019. Ongoing accumulation of plant diversity through habitat connectivity in an 18-year experiment. Science 365, 1478-1480. https://doi.org/10.1126/science.aax8992.

de Juana, E., Garcia, E., 2015. The Birds of the Iberian Peninsula. Bloomsbury Publishing, London, UK.

Dilkina, B., Houtman, R., Gomes, C.P., Montgomery, C.A., McKelvey, K.S., Kendall, K., Graves, T.A., Bernstein, R., Schwartz, M.K., 2016. Trade-offs and efficiencies in optimal budget-constrained multispecies corridor networks. Conserv. Biol. 31 (1), 192-202. https://doi.org/10.1111/cobi.12814.

Fagan, W.F., Calabrese, J.M., 2006. Quantifying connectivity: balancing metric performance with data requirements. In: Crooks, K.R., Sanjayan, M. (Eds.), Connectivity Conservation. Cambridge University Press, New York, NY, pp. 297-317.

Fahrig, L., 2002. Effect of habitat fragmentation on the extinction threshold: a synthesis. Ecol. Appl. 12, 346-353. https://doi.org/10.1890/1051-0761(2002)012[0346: EOHFOT]2.0.CO;2.

Fahrig, L., 2003. Effects of habitat fragmentation on biodiversity. Annu. Rev. Ecol. Evol. Systemat. 34, 487-515. https://doi.org/10.1146/annurev. ecolsys.34.011802.132419. 
Ferraz, G., Nichols, J.D., Hines, J.E., Stouffer, P.C., Bierregaard, R.O., Lovejoy, T.E., 2007. A large-scale deforestation experiment: effects of patch area and isolation on amazon birds. Science 315, 238-241. https://doi.org/10.1126/science.1133097.

Fletcher, R., Burrell, N., Reichert, B., Vasudev, D., Austin, J., 2016. Divergent perspectives on landscape connectivity reveal consistent effects from genes to communities. Curr. Landscape Ecol. Rep. 1, 67-79. https://doi.org/10.1007/ s40823-016-0009-6.

Frey-Ehrenbold, A., Bontadina, F., Arlettaz, R., Obrist, M.K., 2013. Landscape connectivity, habitat structure and activity of bat guilds in farmland-dominated matrices. J. Appl. Ecol. 50, 252-261. https://doi.org/10.1111/1365-2664.12034.

Gonzalez, A., Lawton, J.H., Gilbert, F.S., Blackburn, T., Evans-Freke, I., 1998. Metapopulation dynamics, abundance, and distribution in a microecosystem. Science 281 (5385), 2045-2047.

Goodwin, B.J., 2003. Is landscape connectivity a dependent or independent variable? Landsc. Ecol. 18, 687-699. https://doi.org/10.1023/B:LAND.0000004184.03500. a8.

Haddad, N., Brudvig, L., Clobert, J., Davies, K., Gonzalez, A., Holt, R., Lovejoy, T., Sexton, J., Austin, M., Collins, C., Cook, W., Damschen, E., Ewers, R., Foster, B., Jenkins, C., King, A., Laurance, W., Levey, D., Margules, C., Melbourne, B., Nicholls, A., Orrock, J., Song, D., Townshend, J., 2015. Habitat fragmentation and its lasting impact on Earth ecosystems. Sci. Adv. 1 (2), e1500052 https://doi.org/ 10.1126/sciadv.1500052.

Haddad, N.M., Bowne, D.R., Cunningham, A., Danielson, B.J., Levey, D.J., Sargent, S., Spira, T., 2003. Corridor use by diverse taxa. Ecology 84, 609-615. https://doi.org/ 10.1890/0012-9658(2003)084[0609:CUBDT]2.0.CO;2.

Jacobson, B., Peres-Neto, P.R., 2010. Quantifying and disentangling dispersal in metacommunities: how close have we come? How far is there to go? Landsc. Ecol. 25, 495-507. https://doi.org/10.1007/s10980-009-9442-9.

Jønsson, K.A., Tøttrup, A.P., Borregaard, M.K., Keith, S.A., Rahbek, C., Thorup, K., 2016. Tracking animal dispersal: from individual movement to community assembly and global range dynamics. Trends Ecol. Evol. 31 (3), 204-214. https://doi.org/ 10.1016/j.tree.2016.01.003.

Kang, W., Minor, E.S., Park, C., Lee, D., 2015. Effects of habitat structure, human disturbance, and habitat connectivity on urban forest bird communities. Urban Ecosyst. 18, 857-870. https://doi.org/10.1007/s11252-014-0433-5.

Keeley, A.T.H., Beier, P., Gagnon, J.W., 2016. Estimating landscape resistance from habitat suitability: effects of data source and nonlinearities. Landsc. Ecol. 31, 2151-2162. https://doi.org/10.1007/s10980-016-0387-5.

Klingbeil, B.T., Willig, M.R., 2016. Community assembly in temperate forest birds: habitat filtering, interspecific interactions and priority effects. Evol. Ecol. 30, 703-722. https://doi.org/10.1007/s10682-016-9834-7.

Koen, E.L., Bowman, J., Sadowski, C., Walpole, A.A., 2014. Landscape connectivity for wildlife: development and validation of multispecies linkage maps. Methods Ecol. Evol. 5, 626-633. https://doi.org/10.1111/2041-210X.12197.

Koen, E.L., Garroway, C.J., Wilson, P.J., Bowman, J., 2010. The effect of map boundary on estimates of landscape resistance to animal movement. PloS One 5, e11785. https://doi.org/10.1371/journal.pone.0011785.

Kroll, A.J., Verschuyl, J., Giovanini, J., Betts, M.G., 2017. Assembly dynamics of a forest bird community depend on disturbance intensity and foraging guild. J. Appl. Ecol. 54, 784-793. https://doi.org/10.1111/1365-2664.1277.

Lele, S.R., Moreno, M., Bayne, E., 2012. Dealing with detection error in site occupancy surveys: what can we do with a single survey? J. Plant Ecol. 5 (1), 22-31. https:// doi.org/10.1093/jpe/rtr042.

Leonard, P., Duffy, E., Baldwin, R., McRae, B., Shah, V., Mohapatra, T., 2016. GFlow: software for modelling circuit theory-based connectivity at any scale. Methods Ecol. Evol. 8, 519-526. https://doi.org/10.1111/2041-210X.12689.

Lindenmayer, D., 1994. Wildlife corridors and the mitigation of logging impacts on fauna in wood-production forests in south-eastern Australia: a review. Wildl. Res. 21, 323-340. https://doi.org/10.1071/WR9940323.

Lindenmayer, D.B., Blanchard, W., Foster, C.N., Scheele, B.C., Westgate, M.J., Stein, J., Crane, M., Florance, D., 2020. Habitat amount versus connectivity: an empirical study of bird responses. Biol. Conserv. 241, 108377. https://doi.org/10.1016/j. biocon.2019.108377.

Lindenmayer, D.B., Northrop-Mackie, A.R., Montague-Drake, R., Crane, M., Michael, D., Okada, S., Gibbons, P., 2012. Not all kinds of revegetation are created equal: revegetation type influences bird assemblages in threatened Australian woodland ecosystems. PloS One 7, e34527. https://doi.org/10.1371/journal.pone.0034527.

Liu, C., Berry, P.M., Dawson, T.P., Pearson, R.G., 2005. Selecting thresholds of occurrence in the prediction of species distributions. Ecography 28, 385-393. https://doi.org/10.1111/j.0906-7590.2005.03957.x.

Liu, C., Newell, G., White, M., Bennett, A.F., 2018. Identifying wildlife corridors for the restoration of regional habitat connectivity: a multispecies approach and comparison of resistance surfaces. PloS One 13 (11), e0206071. https://doi.org/10.1371/ journal.pone.0206071.

Loos, J., Hanspach, J., Wehrden, H., Beldean, M., Moga, C.I., Fischer, J., 2015. Developing robust field survey protocols in landscape ecology: a case study on birds, plants and butterflies. Biodivers. Conserv. 24, 33-46. https://doi.org/10.1007/ s10531-014-0786-3.

Manel, S., Williams, H.C., Ormerod, S.J., 2001. Evaluating presence - absence models in ecology : the need to account for prevalence. J. Appl. Ecol. 38, 921-931. https://doi. org/10.1046/j.1365-2664.2001.00647.x.

Martensen, A.C., Pimentel, R.G., Metzger, J.P., 2008. Relative effects of fragment size and connectivity on bird community in the Atlantic Rain Forest: implications for conservation. Biol. Conserv. 141 (9), 2184-2192. https://doi.org/10.1016/j. biocon.2008.06.008.
Martin, C.A., Proulx, R., 2016. Habitat geometry, a step toward general bird community assembly rules in mature forests. For. Ecol. Manag. 361, 163-169. https://doi.org/ 10.1016/j.foreco.2015.11.019.

McClure, M.L., Hansen, A.J., Inman, R.M., 2016. Connecting models to movements: testing connectivity model predictions against empirical migration and dispersal data. Landsc. Ecol. 31, 1419-1432. https://doi.org/10.1007/s10980-016-0347-0.

McRae, B.H., Dickson, B.G., Keitt, T.H., Shah, V.B., 2008. Using circuit theory to model connectivity in ecology, evolution, and conservation. Ecology 89, 2712-2724. https://doi.org/10.1890/07-1861.1.

Morelli, F., Pruscini, F., Santollini, R., Perna, P., Benedetti, Y., Sisti, D., 2013. Landscape heterogeneity metrics as indicators of bird diversity: determining the optimal spatial scales in different landscapes. Ecol. Indicat. 34, 372-379. https://doi.org/10.1016/j. ecolind.2013.05.021.

Mortelliti, A., Amori, G., Boitani, L., 2010. The role of habitat quality in fragmented landscapes: a conceptual overview and prospectus for future research. Oecologia 163, 535-547. https://doi.org/10.1007/s00442-010-1623-3.

Oksanen, J., Blanchet, F.G., Friendly, M., Kindt, R., Legendre, P., McGlinn, D., Minchin, P.R., O’Hara, R.B., Simpson, G.L., Solymos, P., Stevens, M.H.H., Szoecs, E., Wagner, H., 2017. Vegan: Community Ecology Package. R Package Version 2.4-4. https://CRAN.R-project.org/package=vegan.

Palmeirim, J.M., Rabaça, J.E., 1994. A method to analyze and compensate for time-ofday effects on bird counts. J. Field Ornithol. 65 (1), 17-26.

Poniatowski, D., Löffler, F., Stuhldreher, G., Borchard, F., Krämer, B., Fartmann, T., 2016. Functional connectivity as an indicator for patch occupancy in grassland specialists. Ecol. Indicat. 67, 735-742. https://doi.org/10.1016/j. ecolind.2016.03.047.

Prevedello, J.A., Forero-Medina, G., Vieira, M.V., 2011. Does land use affect perceptual range? Evidence from two marsupials of the Atlantic Forest. J. Zool. 284, 53-59. https://doi.org/10.1111/j.1469-7998.2010.00783.x.

Puddu, G., Maiorano, L., 2016. Combining multiple tools to provide realistic potential distributions for the mouflon in Sardinia: species distribution models, spatial pattern analysis and circuit theory. Hystrix 27. https://doi.org/10.4404/hystrix-27.1-11695.

QGIS Development Team, 2013. QGIS Geographic Information System, Open Source Geospatial Foundation Project. http://qgis.osgeo.org.

R Development Core Team, 2013. R: a Language and Environment for Statistical Computing. R Foundation for Statistical Computing, Vienna.

Revilla, E., Wiegand, T., 2008. Individual movement behavior, matrix heterogeneity, and the dynamics of spatially structured populations. P. Natl. Acad. Sci. USA 105 (49), 19120-19125. https://doi.org/10.1073/pnas.0801725105.

Ries, L., Fletcher Jr., R.J., Battin, J., Sisk, T.D., 2004. Ecological responses to habitat edges: mechanisms, models, and variability explained. Annu. Rev. Ecol. Systemat. 35, 491-522. https://doi.org/10.1146/annurev.ecolsys.35.112202.130148.

Ryberg, W.A., Fitzgerald, L.A., 2016. Landscape composition, not connectivity, determines metacommunity structure across multiple scales. Ecography 39 , 932-941. https://doi.org/10.1111/ecog.01321.

Salgueiro, P.A., Mira, A., Rabaça, J.E., Santos, S.M., 2018a. Identifying critical thresholds to guide management practices in agro-ecosystems: insights from bird community response to an open grassland-to-forest gradient. Ecol. Indicat. 88, 205-213. https:// doi.org/10.1016/j.ecolind.2018.01.008.

Salgueiro, P.A., Mira, A., Rabaça, J.E., Silva, C., Eufrázio, S., Medinas, D., Manghi, G., Silva, B., Santos, S.M., 2018b. Thinking outside the patch: a multi-species comparison of conceptual models from real-world landscapes. Landsc. Ecol. 33, 353-370. https://doi.org/10.1007/s10980-017-0603-y.

Saura, S., Pascual-Hortal, L., 2007. A new habitat availability index to integrate connectivity in landscape conservation planning: comparison with existing indices and application to a case study. Landsc. Urban Plann. 83, 91-103. https://doi.org/ 10.1016/j.landurbplan.2007.03.005.

Saura, S., Torné, J., 2009. Conefor SENSINODE 2.2: a software package for quantifying the importance of habitat patches for landscape connectivity. Environ. Model. Software 24, 135-139. https://doi.org/10.1016/j.envsoft.2008.05.005.

Söderström, B., Svensson, B., Vessby, K., Glimskär, A., 2001. Plants, insects and birds in semi-natural pastures in relation to local habitat and landscape factors. Biodivers. Conserv. 10, 1839-1863. https://doi.org/10.1023/A:1013153427422.

Solymos, P., Moreno, M., Lele, S.R., 2016. Detect: Analyzing Wildlife Data with Detection Error. R Package Version 0.4-0. http://CRAN.R-project.org/package=detect.

Staddon, P., Lindo, Z., Crittenden, P.D., Gilbert, F., Gonzalez, A., 2010. Connectivity, non-random extinction and ecosystem function in experimental metacommunities. Ecol. Lett. 13, 543-552. https://doi.org/10.1111/j.1461-0248.2010.01450.x.

Stouffer, P., Bierregaard, R., Strong, C., Lovejoy, T., 2006. Long-term landscape change and bird abundance in amazonian rainforest fragments. Conserv. Biol. 20 (4), 1212-1223. https://doi.org/10.1111/j.1523-1739.2006.00427.x.

Svendsen, J., Sell, H., Bøcher, P., Svenning, J.C., 2015. Habitat and nest site preferences of Red-backed Shrike (Lanius collurio) in western Denmark. Ornis Fenn. 92, 63-75.

Taylor, P., Fahrig, L., Henein, K., Merriam, G., 1993. Connectivity is a vital element of landscape structure. Oikos 68 (3), 571-573 https:doi.org/10.2307/3544927.

Tischendorf, L., Fahrig, L., 2000. On the usage and measurement of landscape connectivity. Oikos 90, 7-19. https://doi.org/10.1034/j.1600-0706.2000.900102.x.

Trainor, A.M., Walters, J.R., Morris, W.F., Sexton, J., Moody, A., 2013. Empirical estimation of dispersal resistance surfaces: a case study with red-cockaded woodpeckers. Landsc. Ecol. 28, 755-767. https://doi.org/10.1007/s10980-0139861-5.

Valerio, F., Carvalho, F., Barbosa, A.M., Mira, A., Santos, S.M., 2019. Accounting for connectivity uncertainties in predicting roadkills: a comparative approach between path selection functions and habitat suitability models. Environ. Manag. 64, 329-343. https://doi.org/10.1007/s00267-019-01191-6. 
van Etten, J., 2017. R package gdistance: distances and routes on geographical grids. J. Stat. Software 76 (1), 1-21. https://doi.org/10.18637/jss.v076.i13.

Vasudev, D., Fletcher, R.J., Goswami, V.R., Krishnadas, M., 2015. From dispersal constraints to landscape connectivity: lessons from species distribution modeling. Ecography 38, 967-978. https://doi.org/10.1111/ecog.01306.

Velázquez, J., Gutiérrez, J., García-Abril, A., Hernando, A., Aparicio, M., Sánchez, B. 2019. Structural connectivity as an indicator of species richness and landscape diversity in Castilla y León (Spain). For. Ecol. Manag. 432, 286-297. https://doi.org/ 10.1016/j.foreco.2018.09.035.

Venables, W.N., Ripley, B.D., 2002. Modern Applied Statistics with S, fourth ed. Springer, New York.
Viljur, M.L., Teder, T., 2018. Disperse or die: colonisation of transient open habitats in production forests is only weakly dispersal-limited in butterflies. Biol. Conserv. 218, 32-40. https://doi.org/10.1016/j.biocon.2017.12.006.

Vogt, P., 2016. GuidosToolbox (graphical user interface for the description of image objects and their shapes). Available from: http://forest.jrc.ec.europa.eu/download/ software/guidos.

Wang, F., McShea, W.J., Li, S., Wang, D., 2018. Does one size fit all? A multispecies approach to regional landscape corridor planning. Divers. Distrib. 24, 415-425. https://doi.org/10.1111/ddi.12692.

Whitlock, M.C., Ingvarsson, P.K., Hatfield, T., 2000. Local drift load and the heterosis of interconnected populations. Heredity 84, 452-457. https://doi.org/10.1046/j.13652540.2000.00693.x. 